\title{
Traumatic flail chest injuries and the benefits of epidural analgesia
}

\author{
Alhadhrami B' ${ }^{*}$, Babsail A², Elhusseini $\mathrm{M}^{2}$, Alhabboubi $\mathrm{M}^{2}$ and Chughtai $\mathrm{T}^{2}$ \\ ${ }^{1}$ Royal Hospital, Muscat, Oman \\ ${ }^{2}$ Division of Trauma surgery, Department of Surgery, Montreal General Hospital, McGill University Health Center, Montreal, Canada
}

\begin{abstract}
Introduction: Many poly-trauma patients sustain chest wall injuries. Flail chest is considered one of the uncommon injuries that may happen in traumatized patients and may increase morbidity and mortality in polytrauma patients. Pulmonary contusion, mechanical ventilation, pneumonia, sepsis and poor pain control are expected to be common complications in patients sustaining chest wall injuries. We hypothesize that the use of epidural analgesia can lead to improved clinical outcomes in this group of patients.

Methodology: A retrospective study conducted for the years 2008 - 2013 for patients admitted to a level 1 trauma center (Figure 1 ). Patients were diagnosed with flail chest by clinical exam and imaging. Trauma registry was queried to study modalities of pain control; especially the use of epidural. We divided the patients to two groups; those who had received epidural analgesia and those who did not have epidural analgesia. A logistic regression model was developed to identify independent predictors of 30 days in hospital mortality.

Results: 180 patients had flail chest; with a mean age was 57.4 years. There were $74.4 \%$ males. There were $43.3 \%$ who had a chest tube, $23.8 \%$ who developed pneumonia and $6.7 \%$ who had tracheostomy. 79 patients (44.4\%) had epidural analgesia. ISS was 26.19 for patients with epidural analgesia and 30 for patients without epidural (p-value 0.02). The mean Hospital length of stay (LOS) was 18.46 days and the 30 days mortality was $3 \%$ for the epidural group V.S $10 \%$ for the non-epidural group ( $p$-value 0.058). Logistic regression analysis for 30-day mortality revealed a significant association in the group with epidural analgesia for Age, ISS score, Hospital LOS and pneumonia.

Conclusion: Epidural analgesia as pain control for patients with flail chest is understudied. This study demonstrates a significant statistical reduction in mortality with the use of epidural in patients diagnosed with flail chest sustained in a trauma setting. There was a significant statistical difference in ISS scores between both groups. This difference can be attributed to head injuries and other complications that may restrict the use of epidural analgesia. Further randomized studies are needed to evaluate the superior efficiency of epidural analgesia over standard pain control modalities in flail chest in trauma patients.
\end{abstract}

\section{Introduction}

Severe blunt chest trauma continues to be one of the leading causes of morbidity and mortality in both young and old trauma victims [1]. Among the different types of blunt chest injury, flail chest is one of the worst, and is likely the most common serious injury to the thorax seen by clinicians $[2,3]$.

Flail chest is traditionally described as the paradoxical movement of a segment of chest wall caused by fractures of three or more consecutive ribs anteriorly and posteriorly within each rib [4]. It occurs when a segment of the thoracic cage is separated from the rest of the chest wall, leading to paradoxical movement of that segment. A segment of the chest wall that is flail is unable to contribute negative pressure to generate lung expansion [5]. Variations include posterior flail segments, anterior flail segments, and flail including the sternum with ribs on both sides of the thoracic cage fractured.

The exact incidence of flail chest is not precisely known. In 1990, Champion, et al. documented 75 patients with flail chest injuries in The Major Trauma Outcomes Study of more than 80,000 patients [6]. In 1995, Ahmed and Mohyuddin documented 64 cases over a 10-year period [7]. Borman evaluated data from the Israel National Trauma Registry, and noted 262 flail chest diagnoses in 11,966 chest injuries (118,211 total patients) examined between 1998 and 2003 [8].
Unfortunately, flail chest is associated with a higher morbidity compared with multiple rib fractures [9]. In a recent review of outcomes and treatment practices from the national trauma databank, Deghan, et al. concluded that patients who have sustained a flail chest have significant morbidity (ICU admission, $82 \%$; mechanical ventilation, 59\%; need for chest tube, $44 \%$; tracheostomy, $21 \%$; ARDS, $14 \%$; sepsis, $7 \%)$ and a high rate of mortality (16\%) [10]. In addition, pulmonary contusions, prolonged mechanical ventilation, pneumonia, sepsis and poor pain control are common among patients sustaining flail chest injuries [7,10-12].

Current emergency treatment of the flail chest should initially follow the principles of advanced trauma life support (ATLS), including adequate analgesia, which is a crucial part of management. However, there is currently some ongoing discussion as to which analgesia modality would be most beneficial to the flail chest patient. In 1975, Trinkle, et al. provided compelling evidence that many

Correspondence to: Alhadhrami B, MD, Royal Hospital, Muscat, Oman, E-mail: drbader85@hotmail.com

Key words: chest injuries, epidural analgesia, trauma patients, pain control

Received: January 04, 2017; Accepted: January 20, 2017; Published: January 24, 2017 
patients fared better with adequate pain control and pulmonary toilet (including medical management of their pulmonary injury) than those placed on mechanical ventilation [13], which remains the standard today. Patient-controlled analgesia (PCA) machines, oral pain medications, and indwelling epidural catheters form the mainstay of current pain management. While the effects of PCA and oral pain medications are well studied [14], conclusions on the benefits derived from epidural analgesia are inconsistent [15]. Studies in the past have demonstrated that epidural analgesia provides superior pain relief and improves pulmonary function tests when compared to intravenous opioids for patients with rib fractures [14,16,17]. In 2004, Bulger, et al. concluded that epidural analgesia is associated with a decrease in the rate of nosocomial pneumonia and a shorter duration of mechanical ventilation after rib fractures [18], and in 2014, Gage, et al. concluded that epidural catheter placement was associated with a significantly decreased risk of mortality in patients with blunt thoracic injury with three or more rib fractures [15]. While these studies, along with others, have provided insight into the benefits of epidural analgesia in multiple rib fracture management, no studies were found discussing the benefits of epidural analgesia specifically in flail chest injuries, which led us to hypothesize that better pain control by the use of epidural analgesia leads to improved clinical outcomes in this group of patients (Figure 2 and 3 ).

\section{Methodology}

A retrospective database review was carried for the years 2008-
2013. The study was conducted at The Montreal General Hospital (MGH), Montreal, Canada, a level 1 trauma center affiliated with the McGill University Health Center (MUHC).

In order to study the effects of epidural analgesia, we divided our patients into two groups; those who received epidural analgesia and those who did not.

Patients' charts, electronic medical records and ICU sheets were consulted to identify their characteristics. The primary outcome of interest was to evaluate the potential benefits of administering epidural analgesia to the flail chest patient, with our hypothesis being that this analgesic modality would show a superior benefit in regards to pain control and reducing complications, namely, hospital length of stay (LOS), ICU LOS, pneumonia, mortality, and sepsis.

Data was summarized using methods of means with standard deviations (SD) and medians with inter quartile ranges (IQR) for continuous data and ratios for categorical data. Student T or MannWhitney tests were used to describe continuous data; Chi-square or Fischer exact tests were used to describe categorical data, as appropriate. A logistic regression model was developed to identify independent predictors of 30-day in-hospital mortality. Statistical analysis was carried out using the SPSS software (version 2.0) (SPSS Inc., Chicago, IL), with consideration of a $p$ value of $<0.05$ as a statistically significant.

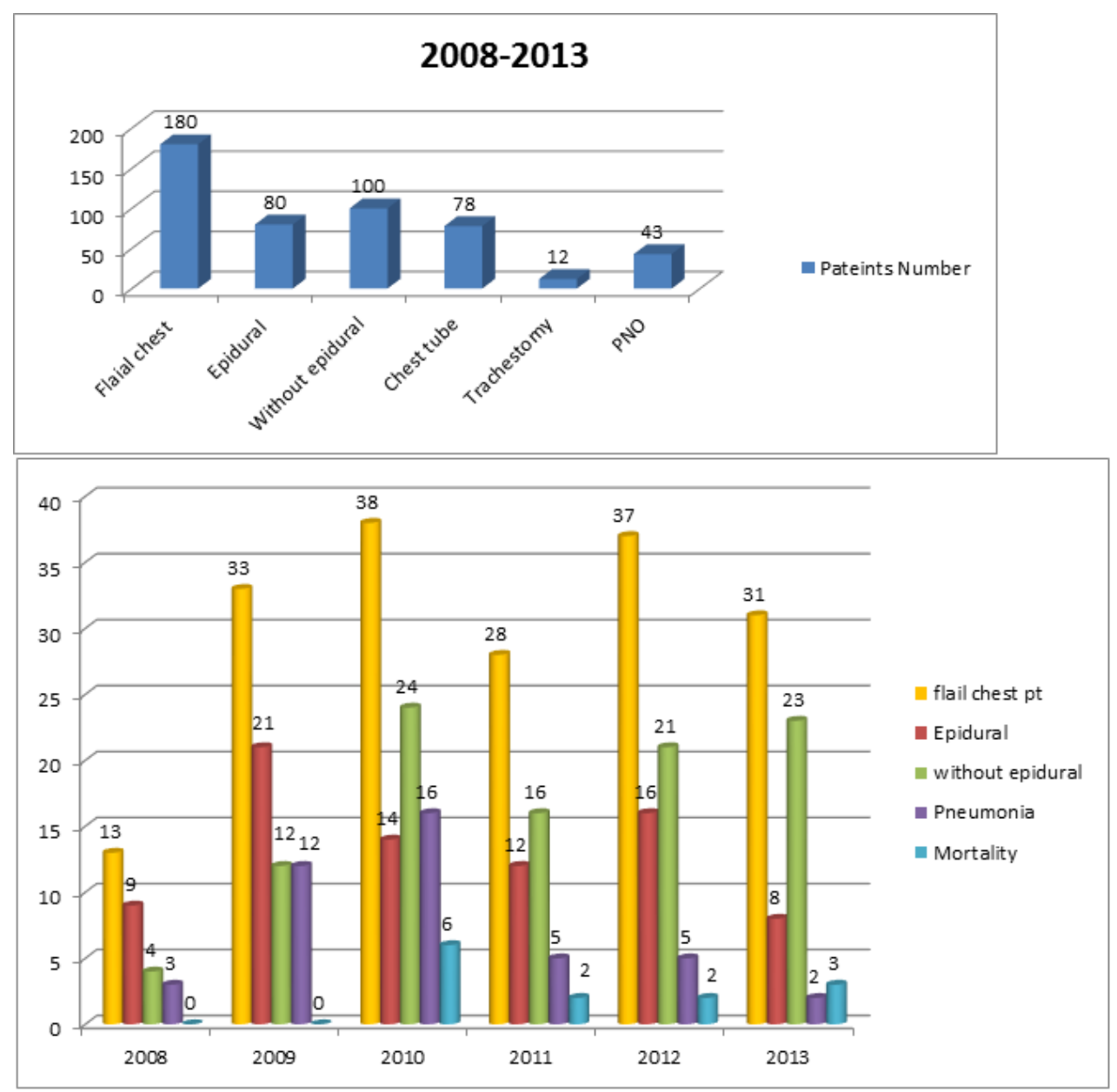

Figure 1. Patients admitted to a level 1 trauma centre. 
Patient with Epidural $\square$ Mortality $\square$ Pne $\square$ Sepsis
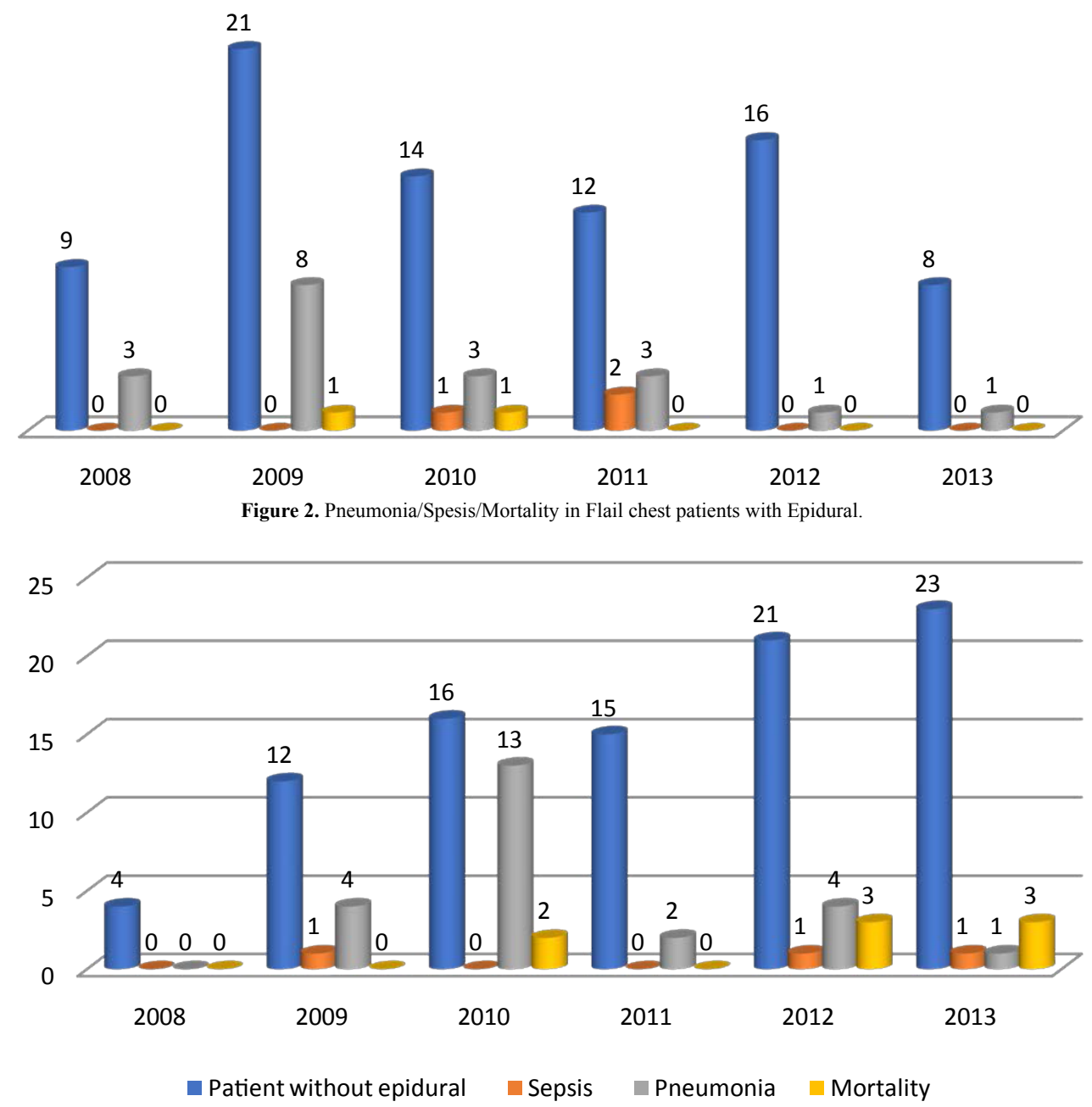

Figure 3. Sepsis/Pneumonia/Mortality in Flail chest patients without Epidural.

\section{Results}

180 patients had flail chest; with mean age was 57.4 years. There were $74.4 \%$ males. There were $43.3 \%$ who had a chest tube, $23.8 \%$ who developed pneumonia and $6.7 \%$ who had tracheostomy. 79 patients (44.4\%) had epidural analgesia. ISS was 26.19 for patients with epidural analgesia and 30 for patients without epidural (p-value 0.02 ). The mean Hospital length of stay (LOS) was 18.57 days in the epidural group vs. 20.4 (25.5) in the group without epidural and the 30 days mortality was $3.8 \%$ for the epidural group vs $11.5 \%$ for the non-epidural group (p-value 0.058) (table-1). Logistic regression analysis for 30 days mortality revealed significant p-value $0.002,0.006,0.003$ and 0.028 in the group with epidural analgesia for Age, ISS score, Hospital LOS and pneumonia respectively (Table 2,3 and 4).

\section{Discussion}

Rib fractures are a common injury in the blunt trauma population with a reported incidence of $10 \%$ among patients admitted to a regional trauma center [19].
Table 1. Baseline demographic data for 180 patients with flail chest enrolled in the study from April 2008 - Dec.2013.

\begin{tabular}{|l|c|}
\hline Flail chest patients & $\mathbf{N}=\mathbf{1 8 0}$ \\
\hline Age & \\
Mean (SD) & $57.4(17.7)$ \\
Median (IQR) & $59(44-70.75)$ \\
\hline Sex & \\
Male & $74.4 \%$ \\
Female & $25.6 \%$ \\
\hline ISS & \\
Mean (SD) & $28.2(11.8)$ \\
Median (IQR) & $26(20-35.75)$ \\
\hline Ventilation Hours (SD) & $232.86(306.6)$ \\
\hline ICU LOS & \\
Mean (SD) & $9.55(11.6)$ \\
Median (IQR) & $5(2-13)$ \\
\hline Hospital LOS & $18.9(20.5)$ \\
Mean(SD) & $11(6-25)$ \\
\hline Median(IQR) & $44.4 \%$ \\
\hline Epidural & $6.7 \%$ \\
\hline Tracheostomy & $43.3 \%$ \\
\hline Chest tube & $23.8 \%$ \\
\hline Pneumonia & \\
\hline
\end{tabular}


Table 2. Univariate analysis of variances revealed significant $(\mathrm{P}$ value $<0.05)$ difference in ISS and hospitals length of stay.

\begin{tabular}{|c|c|c|c|}
\hline Variables & $\begin{array}{l}\text { Flail chest with epidural } \\
\qquad(\mathrm{N}=\mathbf{8 0})\end{array}$ & Flail chest without epidural $(\mathrm{N}=100)$ & P Value \\
\hline \begin{tabular}{|l|} 
Sex \\
Male \\
Female
\end{tabular} & $\begin{array}{l}59 / 80 \\
21 / 80\end{array}$ & $\begin{array}{l}75 / 100 \\
25 / 100\end{array}$ & 0.491 \\
\hline Age (SD) & $57.9(17.1)$ & $57(18.2)$ & 0.929 \\
\hline \begin{tabular}{|l} 
ISS \\
Mean (SD) \\
Median (IQR)
\end{tabular} & $\begin{array}{l}26.19(11.5) \\
24(17-34)\end{array}$ & $\begin{array}{l}29.91(11.9) \\
29(21-38)\end{array}$ & $0.022^{*}$ \\
\hline Ventilation Hours & 241.69 & 225.6 & 0.243 \\
\hline $\begin{array}{l}\text { ICU LOS } \\
\text { Mean (SD) } \\
\text { Median (IQR) }\end{array}$ & $\begin{array}{l}9.27(9.7) \\
5(2-12.5)\end{array}$ & $\begin{array}{l}9.75(14) \\
7(2.5-15)\end{array}$ & 0.360 \\
\hline $\begin{array}{l}\text { Hospital LOS } \\
\text { Mean (SD) } \\
\text { Median (IQR) }\end{array}$ & $\begin{array}{l}18.46(14.9) \\
14(4.25-28)\end{array}$ & $\begin{array}{c}19.27(24.3) \\
10(9-25)\end{array}$ & $0.042^{\prime \prime}$ \\
\hline 30 days Mortality & $3.8 \%(3 / 80)$ & $11 \%(11 / 100)$ & 0.061 \\
\hline Rib surgery & $5 \%(4 / 80)$ & $1 \%(1 / 100)$ & 0.122 \\
\hline Pneumonia & $23.8 \%(19 / 80)$ & $24 \%(24 / 100)$ & 0.556 \\
\hline Sepsis & $2.5 \%(2 / 80)$ & $3 \%(3 / 100)$ & 0.604 \\
\hline
\end{tabular}

Table 3. Logistic regression analysis for variables predicating 30 days mortality in flail chest patients.

\begin{tabular}{|l|l|c|c|c|}
\hline \multirow{2}{*}{ Variables } & \multirow{2}{*}{ Odds Ratio } & \multicolumn{2}{|c|}{$95 \%$ C.I } & \multirow{2}{*}{ P Value } \\
\cline { 3 - 5 } & 0.352 & Lower & Upper & \\
\hline Epidural & 1.105 & 0.055 & 2.241 & 0.269 \\
\hline ISS & 0.817 & 1.038 & 1.176 & $0.002^{*}$ \\
\hline Hospital LOS & 1.085 & 0.708 & 0.944 & $0.006^{*}$ \\
\hline Age & 8.780 & 1.028 & 1.145 & $0.003^{*}$ \\
\hline Pneumonia & 1.268 & 60.788 & $0.028^{*}$ \\
\hline
\end{tabular}

Table 4. Logistic regression analysis for variables predicating epidural in flail chest patients.

\begin{tabular}{|l|l|c|c|c|}
\hline \multirow{2}{*}{ Variables } & \multirow{2}{*}{ Odds Ratio } & \multicolumn{2}{|c|}{$95 \%$ C.I } & \multirow{2}{*}{ P Value } \\
\cline { 3 - 5 } & 0.582 & Lower & Upper & \\
\hline Age & 0.977 & 0.987 & 1.023 & 0.582 \\
\hline ISS & 1.031 & 0.949 & 1.005 & 0.103 \\
\hline Sex & 1.000 & 0.518 & 2.053 & 0.930 \\
\hline Hospital stay & 0.347 & 0.985 & 1.016 & 0.959 \\
\hline 30 days Mortality & & 0.085 & 1.415 & 0.140 \\
\hline
\end{tabular}

A flail chest, defined as three or more consecutive rib fractures in two or more locations creating a flail segment, can lead to numerous complications, such as chest wall instability, asynchronous movement of the flail segment, and paradoxical chest motion. It may also cause physical deformity of the chest wall and loss of thoracic volume [11]. These in turn lead to decreased lung volume, atelectasis, chest tightness, dyspnea, and chronic pain [12,20].

One of the cornerstones of management of multiple rib fractures and flail chest is appropriate analgesia [11,12,21]. We chose to study the benefits of epidural analgesia in patients with flail chest because we believe that this is an understudied topic and we adopt a more aggressive approach at our center with epidural use.

The main advantage of epidural analgesia over narcotics is that it is non-sedating, and patients can generally remain awake to cooperate with respiratory therapies [22]. However, there are also numerous contraindications to epidural catheter placement in trauma patients, including thoracic vertebral fractures, spinal cord injury, coagulopathy, unstable pelvis, and severe head injury $[23,24]$.

Our study demonstrated that there is a trend towards reduction in mortality with the use of epidural analgesia in flail chest patients, along with a reduction in the overall ICU and hospital LOS, in comparison to patients who did not receive epidural analgesia. Additionally, we found lower incidences of flail chest complications, namely sepsis and pneumonia. This supports the conclusion of other studies, which reported improved outcomes and lower complications in flail chest patients who were managed with epidural analgesia compared with other methods of pain control $[18,21,25,26]$. These studies found that compared with intravenous narcotic use, epidural catheters allow for improved subjective pain perception, pulmonary functions tests, lower rates of pneumonia, as well as decreased length of time on a mechanical ventilator or ICU stay $[21,25,26]$. They also reported lower rates of complications such as respiratory depression, somnolence, and gastrointestinal symptoms [21].

An interesting observation in our study was the difference in ISS score [27] in the two groups of patients. The patients who were managed with epidural analgesia had lower ISS scores than those who were not (26.4 vs 30.3 ). This can be attributed to the nature of the injuries in the high ISS score patients who were more likely to have contraindications to receiving epidural anesthesia, such as increased intracranial pressure, coagulopathy, and spine trauma, [28,29] which ultimately precluded them from receiving epidural anesthesia, and necessitated their management with other modalities of pain control.

\section{Limitations}

One of the limitation that not all patients were included in the epidural group due to numerous contraindications to epidural catheter placement in trauma patients, including thoracic vertebral fractures, spinal cord injury, coagulopathy, unstable pelvis, and severe head injury. ${ }^{23,24}$ Other limitations to this study is that it is a retrospective study with all it's inherent limitations. It was conducted in only one Trauma center and could not be generalized to a larger population. The sample size for this study is considered small and a larger sample could yield more significant data.

\section{Conclusion}

Although the use of epidural analgesia as method of pain control for patients with flail chest remains to be relatively understudied, multiple studies and outcome reviews seem to consistently support its use. Similarly, our study also demonstrated positive outcomes in flail 
chest patients managed with epidural analgesia. Given the high rates of morbidity and mortality in patients with a flail chest injury, it may be of benefit to standardize the modality of analgesia administered to these patients. However, large randomized controlled trials are needed before standardization can take place.

\section{References}

1. Kilic D, Findikcioglu A, Akin S, Akay TH, Kupeli E, et al. (2011) Factors affecting morbidity and mortality in flail chest: comparison of anterior and lateral location. Thorac Cardiovasc Surg 59: 45-48.[Crossref]

2. Adegboye VO, Ladipo JK, Brimmo IA, Adebo AO (2002) Blunt chest trauma. Afr J Med Med Sci 31: 315-320.[Crossref]

3. Athanassiadi K, Gerazounis M, Theakos N (2004) Management of 150 flail chest injuries: analysis of risk factors affecting outcome. Eur J Cardiothorac Surg 26: 373376.[Crossref]

4. Kaiser LRSS (2004) Thoracic Trauma. Surgical Foundations, Essentials of Thoracic Surgery, Philadelphia, PA, Elvisor p: 104.

5. Pelosi P1, Cereda M, Foti G, Giacomini M, Pesenti A (1995) Alterations of lung and chest wall mechanics in patients with acute lung injury: effects of positive endexpiratory pressure. Am J Respir Crit Care Med 152: 531-537.[Crossref]

6. Champion HR, Copes WS, Sacco WJ (1990) The Major Trauma Outcome Study: establishing national norms for trauma care. J Trauma 30: 1356-1365.

7. Ahmed Z, Mohyuddin Z (1995) Management of flail chest injury: internal fixation versus endotracheal intubation and ventilation. J Thorac Cardiovasc Surg 110: 16761680.

8. Borman JB, Aharonson-Daniel L, Savitsky B, Peleg K (2006) Unilateral flail chest is seldom a lethal injury. Emerg Med J 23: 903-905

9. Velmahos GC, Vassiliu P, Chan LS, Murray JA, Berne TV, et al. (2002) Influence of flail chest on outcome among patients with severe thoracic cage trauma. Int Surg 87: 240-244.[Crossref]

10. Dehghan N, de Mestral C, McKee MD, Schemitsch EH, Nathens A (2014) Flail ches injuries: a review of outcomes and treatment practices from the National Trauma Data Bank. J Trauma Acute Care Surg 76: 462-468.[Crossref]

11. Nirula R, Diaz JJ Jr, Trunkey DD, Mayberry JC (2009) Rib fracture repair: indications, technical issues, and future directions. World J Surg 33: 14-22.[Crossref]

12. Lafferty PM, Anavian J, Will RE, Cole PA (2011) Operative treatment of chest wall injuries: indications, technique, and outcomes. J Bone Joint Surg Am 93: 97Y110.

13. Trinkle JK, Richardson JD, Franz JL (1975) Management of flail chest withou mechanical ventilation. Ann Thorac Surg 19: 355-363.
14. Mackersie RC, Karagianes TG, Hoyt DB, Davis JW (1991) Prospective evaluation of epidural and intravenous administration of fentanyl for pain control and restoration of ventilatory function following multiple rib fractures. J Trauma 31: 443-449.

15. Gage, Alexis, Rivara, Frederick, Wang, et al. (2014) The effect of epidural placement in patients after blunt thoracic trauma. J Trauma Acute Care Surg 76: 39-46.

16. Moon MR, Luchette FA, Gibson SW, Crews J, Sudarshan G, et al. (1999) Prospective, randomized comparison of epidural versus parenteral opioid analgesia in thoracic trauma. Ann Surg 229: 684-691.

17. Wu CL, Jani ND, Perkins FM, Barquist E (1999) Thoracic epidural analgesia versus intravenous patient-controlled analgesia for the treatment of rib fracture pain after motor vehicle crash. $J$ Trauma 47: 564-567.[Crossref]

18. Bulger EM, Edwards T, KlotzP, Jurkovich GJ (2004) Epidural analgesia improves outcome after multiple rib fractures. Surgery 136: 426-430.

19. Ziegler DW, Agarwal NN (1994) The morbidity and mortality of rib fractures. $J$ Trauma37: 975-979.[Crossref]

20. Engel C, Krieg JC, Madey SM, Long WB, Bottlang M (2005) Operative chest wal fixation with osteosynthesis plates. J Trauma 58: 181-186.[Crossref]

21. Simon B, Ebert J, Bokhari F, Capella J, Emhoff T, et al. (2012) Management of pulmonary contusion and flail chest: an Eastern Association for the Surgery of Trauma practice management guideline. J Trauma Acute Care Surg 73: S351YS361.

22. Worthley LI (1985) Thoracic epidural in the management of chest trauma. A study of 161 cases. Intensive Care Med 11: 312-315.[Crossref]

23. Bulger EM, Arneson MA, Mock CN, Jurkovich GJ (2000) Rib fractures in the elderly. J Trauma 48: 1040-1046.[Crossref]

24. Yeh DD, Kutcher ME, Knudson MM, Tang JF (2012) Epidural analgesia for blunt thoracic injury--which patients benefit most? Injury 43: 1667-1671.[Crossref]

25. Simon BJ, Cushman J, Barraco R, Lane V, Luchette FA, et al. (2005) Pain management guidelines for blunt thoracic trauma. J Trauma 59: 1256-1267.[Crossref]

26. Luchette FA, Radafshar SM, Kaiser R, Flynn W, Hassett JM (1994) Prospective evaluation of epidural versus intrapleural catheters for analgesia in chest wall trauma. J Trauma36:865Y869.

27. Baker SP, O’Neill B, Haddon W Jr, Long WB (1974) The injury severity score: a method for describing patients with multiple injuries and evaluating emergency care. $J$ Trauma 14: 187-196.[Crossref]

28. Wheatley RG, Schug SA, Watson D (2001) Safety and efficacy of postoperative epidural analgesia. Br J Anaesth 87: 47-61.[Crossref]

29. Block BM, Liu SS, Rowlingson AJ, Cowan AR, Cowan JA, et al. (2003) Efficacy of Postoperative Epidural Analgesia - A Meta-analysis. JAMA 290: 1-9.

Copyright: $@ 2017$ Alhadhrami B. This is an open-access article distributed under the terms of the Creative Commons Attribution License, which permits unrestricted use, distribution, and reproduction in any medium, provided the original author and source are credited. 